\title{
Outcome of early use of non-invasive positive pressure ventilation in patients with acute exacerbation of chronic obstructive pulmonary disease
}

\author{
Nadia Ishfaq', Naheed Gul', Neelum Zaka3
}

\begin{abstract}
Objective: To determine the outcome of early use of non-invasive positive pressure ventilation (NIPPV) in Pakistani patients with acute exacerbation of chronic obstructive pulmonary disease.

Methods: This descriptive study was conducted at Shifa International Hospital Islamabad from April 2015 to January 2017. A total of 120 patients with acute exacerbation of chronic obstructive pulmonary disease receiving NIPPV alongside standard therapy were included in the study. The patients were clinically assessed before starting on NIPPV. The parameters of respiratory rate, $\mathrm{pH}$ and $\mathrm{paCO}_{2}$ were monitored and NIPPV was given for six hours to evaluate clinical outcomes and analyze the factors predicting failure (requirement of mechanical ventilation and mortality). Frequency and percentages were calculated for qualitative variables while Mean and Standard Deviation for quantitative variables. Chi-square and t-test were used to see differences in pre and post NIPPV arterial blood gases.

Results: Patients' mean age was $58.88 \pm 10.09$ years. Males were $88(73.3 \%)$ and females were $32(26.7 \%)$. The mean respiratory rate was $24 \pm 1.45$ per minute before and $17.96 \pm 1.35$ per minute after NIPPV $(\mathrm{p}<$ $0.00001)$. The mean $\mathrm{pH}$ before NIPPV was $7.27 \pm 0.04$ and afterwards $7.38 \pm 0.02(\mathrm{p}<0.00001)$. The mean $\mathrm{pCO}_{2}$ was $61.87 \pm 9.60 \mathrm{~mm}$ of $\mathrm{Hg}$ before and $57.46 \pm 6.79 \mathrm{~mm}$ of $\mathrm{Hg}$ after NIPPV $(P<0.0003)$. Twenty Four (20\%) patients required invasive ventilation of which 19 (15.8\%) patients could not survive.

Conclusions: There was remarkable improvement in the arterial blood gases after NIPPV. However, the high mortality rate and significant number of COPD patients requiring mechanical ventilation necessitates further investigation into our population.
\end{abstract}

KEYWORDS: Arterial blood gases, Chronic obstructive pulmonary disease, Non-invasive positive pressure ventilation, Mechanical ventilation, Mortality.

doi: https://doi.org/10.12669/pjms.35.6.857

How to cite this:

Ishfaq N, Gul N, Zaka N. Outcome of early use of non-invasive positive pressure ventilation in patients with acute exacerbation of chronic obstructive pulmonary disease. Pak J Med Sci. 2019;35(6):1488-1492. doi: https://doi.org/10.12669/pjms.35.6.857

This is an Open Access article distributed under the terms of the Creative Commons Attribution License (http://creativecommons.org/licenses/by/3.0), which permits unrestricted use, distribution, and reproduction in any medium, provided the original work is properly cited.

1. Dr. Nadia Ishfaq, FCPS Internal Medicine, Senior Registrar, Department of Medicine.

2. Dr. Naheed Gul, FCPS Internal Medicine,

Associate Professor, Department of Medicine.

3. Dr. Neelum Zaka, MCPS \& FCPS Internal Medicine,

Assistant Professor, Department of Medicine.

1-3: Shifa College of Medicine, Islamabad, Pakistan.

Correspondence:

Dr. Naheed Gul, FCPS Internal Medicine.

Associate Professor Department of Medicine.

Shifa College of Medicine,

Sector H-8/4, 44000, Islamabad, Pakistan.

Mailing Address: House no. 23, Service Road North,

1/8-2, Islamabad, Pakistan.

Email: doctornaheed@live.com

* Received for Publication:

* Revision Received:

* Revision Accepted:

April 8, 2019

August 9, 2019

August 25, 2019

\section{INTRODUCTION}

Chronic Obstructive Pulmonary Disease (COPD) is characterized by progressive partly reversible air flow limitation and lung hyperinflation with major extra pulmonary manifestations and co-morbid conditions. ${ }^{1}$ It is the major health problem and is the $5^{\text {th }}$ and $12^{\text {th }}$ leading cause of death and disability worldwide, respectively. ${ }^{1,2}$ It is the $3^{\text {rd }}$ leading cause of mortality in United States with an expenditure of more than 40 billion dollars. ${ }^{3}$ A survey including Middle East, North Africa and Pakistan reported overall prevalence of COPD to be $3.5 \%$ with up to $2.2 \%$ of patients from Pakistan. ${ }^{4}$ According to

Pak J Med Sci November-December 2019 Vol. 35 No. $6 \quad$ www.pjms.org.pk 1488 
WHO, the number of COPD cases worldwide will increase by three times the total number of COPD cases by the year $2020 .^{1}$

COPD exacerbation is characterized by the deterioration of patient's baseline symptoms including dyspnea, cough and/or sputum which usually requires change in regular medication. ${ }^{1}$ An acute exacerbation of COPD is the main source of admission to hospitals. ${ }^{5}$ A portion of these patients with frequent exacerbations may develop acute respiratory failure requiring Intensive Care Unit (ICU) admission and utilization of large ICU resources. ${ }^{6}$

The first line of cure in patients with Acute Respiratory Failure (ARF) is ventilation. Patients with ARF can be ventilated by either positive or negative pressure invasively or non-invasively. ${ }^{7}$ Mechanical ventilation can be a lifesaving procedure in patients with ARF. ${ }^{5}$ However, the use of artificial way leads to severe infection and carries the risk of trauma to the airways. ${ }^{1}$ Non-invasive ventilation is another safe approach that was developed to avoid these complications in such patients. The early use of NIPPV have shown decrease in intubation rate by $66 \%$ and mortality rate by $9 \%$, thus minimizing ICU and hospital stay. ${ }^{3}$ A research study showed advantages of NIPPV in staying away from the requirement for invasive mechanical ventilation in patients presenting with ARF of various etiology. ${ }^{8}$ With the use of NIPPV, the mortality rate improved to $10.1 \%$ compared to mechanical ventilation $(26 \%)$, while the length of stay in ICU has been reported as 7 to 13 days which is significantly better than invasive mechanical ventilation (10 to 20 days). ${ }^{3}$ In another large study (248 patients) conducted in India, NIPPV showed significant improvement in clinical and blood gas parameters, endotracheal intubation and mortality in certain group of patients. ${ }^{7}$

Theuse of NIPPV forimprovement in arterialblood gases (ABGs) in patients with acute exacerbation of COPD has also been studied in Pakistan. ${ }^{5,9,10}$ The sample sizes were however quite small and data available insignificant to draw definite conclusions. Only one study has determined the effect on mechanical ventilation and mortality in 2001 with only eighteen patients. ${ }^{9}$ The number of patients requiring mechanical ventilation and mortality rate is not well established in our patients receiving NIPPV in combination to standard therapy for acute exacerbation of COPD. The motivation of this study was to find out the frequency of Pakistani population with acute exacerbation of COPD receiving NIPPV alongside standard treatment requiring mechanical ventilation and the overall mortality rate on a large sample size and in a tertiary care hospital with state of the art health facilities. We also investigated the effects on ABGs for comparison to previous studies in Pakistan.

\section{METHODS}

This was a prospective hospital based descriptive study carried out in Department of Medicine at Shifa International Hospital, Islamabad. This was a longitudinal study conducted over a period of 21 months from April 2015 to January 2017. A total of 120 patients with acute exacerbation of chronic obstructive pulmonary disease were included using non-probability (consecutive) sampling technique. Sample size was calculated as 120 using WHO sample size calculator considering $95 \%$ confidence level, absolute precision $6 \%$ and anticipated population proportion $\mathrm{p}=12.5 \%$.

Patients with COPD exacerbation fulfilling the following criteria were included in the study: 1) All age groups 2) Both males and females 3) Dyspnoea at rest or respiratory rate $>25$ breaths per minute and oxygen saturation less than $85 \%$. 4) FEV $1<50 \%$ predicted or PEFR $\leq 100$ litter per minute. 5) ABGs showing $\mathrm{pH}<7.35, \mathrm{~Pa} \mathrm{Co}_{2}>45 \mathrm{mmHg}$ and $\mathrm{PaO}_{2}<60 \mathrm{mmHg}$. Patients with following conditions were excluded from the study:1) Arterial blood $\mathrm{pH}<7.20$ 2) Unconsciousness 3) Unable to clear their airways 4) Un-cooperative, agitated 5) Hemodynamic instability 6) A central nervous system disorder unrelated to hypercapnia associated encephalopathy or hypoxemia.

Institutional review board approval was obtained before starting data collection. (IRB 975250-2018 dated March 31, 2018) Written informed consent was taken and a detailed history followed by rigorous clinical examination of the patients were documented. Respiratory rate and ABGs were taken before Non-invasive positive pressure ventilation (NIPPV). NIPPV was given to patients for at least 6 to 8 hours, during which time the patients were assessed for clinical stability. Clinical signs and ABGs were checked again after 6 to 8 hours of NIPPV. The presence of sustained clinical improvement with decrease in respiratory rate < $24 /$ minutes, presence of normal $\mathrm{pH}, \mathrm{PaCO}_{2}<55$ $\mathrm{mm}$ of $\mathrm{Hg}$ and $\mathrm{O}_{2}$ saturation more than $90 \%$ on $\mathrm{ABG}$ was required before patients were considered for weaning from NIPPV. In case of deterioration in patient's clinical condition and/or ABGs, patients were shifted to Intensive Care Unit (ICU) and 
Table-I: Effect of NIPPV on ABGs and Respiratory Rate $(n=120)$.

\begin{tabular}{lccc}
\hline & Minimum & Maximum & Mean \pm Std. Deviation \\
\hline Before NIPPV pH & 7.20 & 7.34 & $7.2703 \pm 0.04103$ \\
After NIPPV pH & 7.35 & 7.42 & $7.3851 \pm 0.02264$ \\
Before NIPPV pCO 2 & 45.00 & 80.00 & $61.8750 \pm 9.60004$ \\
After NIPPV pCO 2 & 45.00 & 68.00 & $57.4667 \pm 6.79092$ \\
Before NIPPV Resp. Rate & 22.00 & 26.00 & $24.0083 \pm 1.45807$ \\
After NIPPV Resp. Rate & 16.00 & 20.00 & $17.9667 \pm 1.35927$ \\
\hline
\end{tabular}

followed for a week in terms of requirement for mechanical ventilation and any hospital mortality following intervention failure was recorded.

Statistical analysis: Data was analyzed on SPSS Version 10. Frequency and Percentages were computed for qualitative variables like gender, mortality and intubation. Mean and Standard Deviation were computed for quantitative variables like age, respiratory rate, $\mathrm{pH}, \mathrm{pO}_{2}$ and $\mathrm{pCO}_{2}$ before and after NIPPV. Effect modifiers like age and gender were controlled by stratification. Post stratification paired $t$-test was applied to see difference in the pre- and post- NIPPV quantitative variables. chi-square test was used for qualitative variables. A p-value $\leq 0.05$ was considered as significant.

\section{RESULTS}

Out of a total of 120 patients with acute exacerbation of chronic obstructive airway disease, males were $88(73.3 \%)$ and females were $32(26.7 \%)$. Patients age ranged from a minimum of 40 years to a maximum of 75 years with a mean age of $58.88 \pm 10.09(\mathrm{p}=0.002)$. Descriptive statistics for respiratory rate, $\mathrm{pH}$ and $\mathrm{pCO}_{2}$ are given in Table-I below. The parameters of respiratory rate, $\mathrm{pH}$

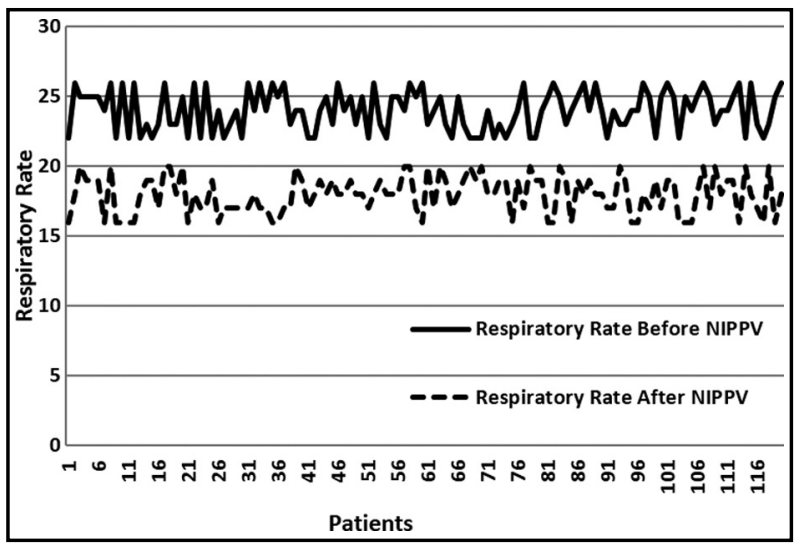

Fig.1: Trends in Respiratory Rate before and after NIPPV. and carbon dioxide $\left(\mathrm{pCO}_{2}\right)$ were measured before and after NIPPV. The mean respiratory rate of the patients was $24 \pm 1.45$ per minute before and 17.96 \pm 1.35 per minute after NIPPV. This difference was statistically significant with $\mathrm{p}$ value of less than < 0.00001 . The individual variation in respiratory rate are shown in Fig.1.

The mean $\mathrm{pH}$ before NIPPV was $7.27 \pm 0.04$ and afterwards was $7.38 \pm 0.02$ with statistically significant difference $(\mathrm{p}<0.00001)$ as shown in Fig. 2. The variations in the $\mathrm{pH}$ level of the study population before and after NIPPV are highlighted in the figure. The mean $\mathrm{pCO}_{2}$ was $61.87 \pm 9.60 \mathrm{~mm}$ of $\mathrm{Hg}$ before and $57.46 \pm 6.79 \mathrm{~mm}$ of $\mathrm{Hg}$ after NIPPV. This difference in $\mathrm{pCO}_{2}$ levels was also statistically significant $(\mathrm{P}<0.0003)$. Overall NIPPV was successful in $80 \%$ of the patients where the patients were weaned off from NIPPV and discharged home safely.

In our study, twenty four $(20 \%)$ patients required endotracheal intubation and invasive ventilation compared to $96(80 \%)$ patients who were safely weaned off which was statistically significant $(p=$ 0.011 ). Out of the 24 patients who were intubated, only five survived making total mortality in hospital as $15.83 \%$ (19 out of 120 patients).

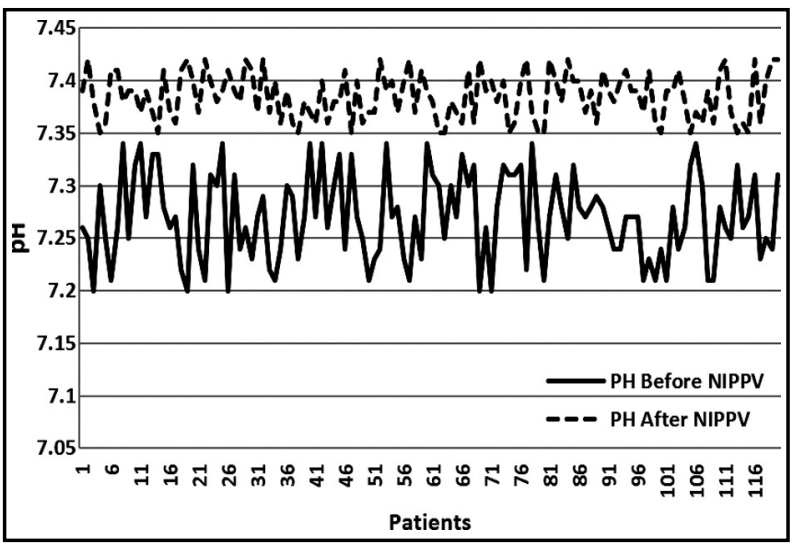

Fig.2: Trends in $\mathrm{pH}$ before and after NIPPV. 


\section{DISCUSSION}

We studied the effect of NIPPV on respiratory rate, arterial blood gases, the number of patients who could be discharged home safely, the need for mechanical ventilation and mortality rate in patients with acute exacerbation of COPD. There was significant difference in term of improvement in respiratory rate and ABGs from the baseline. Our results coincide with earlier studies which reported similar findings for respiratory rate and ABGs. ${ }^{11,12}$ The beneficial effect of NIPPV in our COPD patients with an acute exacerbation could be due to the fact that non-invasive ventilation reduces respiratory muscle activity and improves the breathing pattern (respiratory rate and tidal volume). In addition, gas exchange improves with increasing $\mathrm{pH}$, $\mathrm{PaO}_{2}$ and decreasing $\mathrm{PaCO}_{2}$ and reduction in the diaphragmatic activity. ${ }^{13,14}$

In our study, 96(80\%) patients were discharged home safely while $24(20 \%)$ required mechanical ventilation. All of the 24 patients who did not improve with NIPPV were given mechanical ventilation out of which only $6(4.2 \%)$ recovered. This requires further research into the management of patients who don't improve with NIPPV. Better hospital survival, fewer intubations, less complications and a shorter hospital stay was found in some studies. ${ }^{15,16}$ Nevertheless this needs to be reevaluated in our population as well. Our study results are better than in Bangladesh where NIPPV significantly reduced the need for mechanical ventilation in the non-invasive ventilation group $(40 \%)$ as compared to $73.3 \%$ in the standard group ( $\mathrm{p}=0.01$ ). The in-hospital mortality rate was significantly reduced $(16.7 \%)$ in the non-invasive group as compared with $43.3 \%$ in the standard treatment group $(p=0.04) .{ }^{17}$ The mortality in the noninvasive group was comparable to the mortality in our group of patients where it was $15.83 \%$.

While the findings of our study were comparable to the previous studies ${ }^{5,9,10}$ in Pakistan in terms of improvement in blood gases and respiratory rate, there was a huge difference in the number of patients requiring mechanical ventilation ( $20 \%$ in our study compared to $5.6 \%$ in previous study). ${ }^{9}$ The overall mortality in our patients was more $(15.83 \%)$ compared to previous data $(11 \%) .{ }^{9}$ This difference could be due to the difference in sample size which was very small in the previous study. The high figures with regards to need for mechanical ventilation and mortality warrants more in-depth research into its etiology. Our results concurs with the findings in other parts of the world. This include a systematic review of multiple randomized control trials found that NIPPV improved $\mathrm{pH}$ in one hour, $\mathrm{PaCO}_{2}$ and respiratory rate and significantly reduced the length of hospital stay ${ }^{18}$ however these studies had a control group for comparison compared to our study. While we did not have a control group, we did compare it with the limited results available in Pakistan. Our results highlighted the overall frequency/need for endotracheal intubation and mortality in patients with acute exacerbation of COPD in our population. This study also provides a baseline for future research into the predictive factors determining morbidity and mortality in such patients.

Limitations of the study: This was a hospital based cross-sectional study. Large scale hospital-based studies are required as the prevalence of COPD is gradually increasing in Pakistan. While we didn't use a standard control group, we did compare our results to the data available in Pakistan. Long term follow-up was not done in these patients which could have better explained the outcome. Effect of comorbid conditions was not analyzed which could have contributed to mortality.

\section{CONCLUSION}

There was significant improvement in biochemical and clinical parameters after noninvasive positive pressure ventilation compared to baseline. However, the number of patients with acute exacerbation of COPD in our study requiring mechanical ventilation and the high mortality rate shows that it was underreported from Pakistan previously necessitating the need for further research in our country.

Grant support \& Financial disclosures: None.

Conflict of interest: None.

\section{REFERENCES}

1. Ban A, Ismail A, Harun R, Rahman AA, Sulung S, Mohamed AS. Impact of clinical pathway on clinical outcomes in the management of COPD exacerbation. BMC Pulm Med. 2012;12:27. doi: 10.1186/1471-2466-12-27.

2. Gold PM. The 2007 GOLD Guidelines: a comprehensive care framework. Respir Care. 2009;54(8):1040-1049.

3. Okpala PC, Alexander JL, Ewing H, Tulp OL. The use of noninvasive positive pressure ventilation (NIPPV) and conventional medical care to treat respiratory failure arising from acute exacerbation of COPD: a systematic review. J Appl Med Sci. 2013;2(2):31-41. 
4. Uzaslan E, Mahboub B, Beji M, Nejjori C, Tageldin AM, Khan JA, et al. The burden of chronic obstructive pulmonary disease in the Middle East and North Africa: Results of the BREATHE study. Respir Med. 2012;106(Suppl 2):S45-S59. doi: 10.1016/S0954-6111(12)70014-8

5. Iqbal Z, Zia Ullah, Basit A, Khan MY, Javaid A. Changes in arterial blood gases and respiratory Rate before and after noninvasive positive pressure ventilation in acute exacerbation of chronic Obstructive pulmonary disease. Pak J Chest Med. 2008;14(3):3-8.

6. Alaithan AM, Memon JI, Rehmani RS, Qureshi AA, Salam A. Chronic obstructive pulmonary disease: Hospital and intensive care unit outcomes in the Kingdom of Saudi Arabia. Int J Chron Obstruct Pulmon Dis. 2012;7:819-823. doi:10.2147/copd.s37611.

7. Agarwal R, Gupta R, Agarwal AN, Gupta D. Noninvasive positive pressure ventilation (NIPPV) in acute respiratory failure due to COPD vs other causes: effectiveness and predictors of failure in a respiratory ICU in North India. Int J Chron Obstruct Pulmon Dis. 2008;3(4):737-743. doi: 10.2147//copd.s3454.

8. Chandra D, Stamm JA, Taylor B, Ramos RM, Satterwhite L, Kaishnan JA, et al. Outcome of noninvasive ventilation for acute exacerbation of COPD in the United States, 1998-2008. Am J Respir Crit Care Med. 2012;185:152-159. doi:10.1164/ rccm.201106-1094oc.

9. Rizvi N, Mehmood N, Hussain N. Role of Bi-Pap in acute respiratory failure due to acute exacerbation of COPD. J Pak Med Assoc. 2001;51(12):414-417.

10. Raza A, Malik MI, Jamal Y. Comparison of NIPPV with standard treatment in patients with acute exacerbations of COPD in terms of improvement in ABGs and hospital stay. Pak Armed Forces Med J. 2014;64(1):46-50.

11. Bott J, Carroll MP, Conway JH, Keilty SE, Ward EM, Brown $\mathrm{AM}$, et al. Randomised controlled trial of nasal ventilation in acute ventilatory failure due to chronic obstructive airways disease. Lancet. 1993;341:1555-1557. doi:10.1016/01406736(93)90696-e.

12. Kramer N, Meyer TJ, Meharg J, Cece RD, Hill NS. Randomized, prospective trial of noninvasive positive pressure ventilation in acute respiratory failure. Am J Respir Crit Care Med. 1995;151:1799-1806. doi: 10.1164/ ajrccm.151.6.7767523.
13. Girault C, Chevron V, Richard JC, Daudenthun I, Pasquis $\mathrm{P}$, Leroy J, et al. Physiological effects and optimisation of nasal assist-control ventilation for patients with chronic obstructive pulmonary disease in respiratory failure. Thorax. 1997;52:690-696. doi: 10.1136/thx.52.8.690.

14. Ambrosino N, Nava S, Bertone P, Fracchia C, Rampulla C. Physiologic evaluation of pressure support ventilation by nasal mask in patients with stable COPD. Chest. 1992;101:385-391. doi: 10.1378/chest.101.2.385.

15. Brochard L, Mancebo J, Wysocki M, Lofaso F, Conti G, Rauss $A$, et al. Noninvasive ventilation for acute exacerbations of chronic obstructive pulmonary disease. N Engl J Med. 1995;333:817-822. doi: 10.1056/nejm199509283331301.

16. Elliott MW. Non-invasive ventilation for acute respiratory disease. Br Med Bull. 2004;72:83-97. doi: 10.1093/bmb/ ldh042.

17. Khanum RA, Haque MA, Rehman SMS, Hussain MA, Hassan MR. A controlled trial of noninvasive positive pressure ventilation (NIPPV) in patients of COPD with respiratory failure. Bangladesh Crit Care J. 2013;1(2):86-92.

18. Lightowler JV. Noninvasive positive pressure ventilation to treat respiratory failure resulting from exacerbation of chronic obstructive pulmonary disease: Cochrane systematic review and meta-analysis. BMJ. 2003;326:185187. doi: $10.1136 /$ bmj.326.7382.185.

\section{Author`s Contribution:}

NI: Conceptualization of study, study design, data collection, analysis and write up.

NG: Study design, Literature review, data analysis and write up of manuscript.

NZ: Study design, data collection and review of the manuscript. 